TITLE:

\title{
Ascidian homologs of mammalian thyroid transcription factor-1 gene are expressed in the endostyle
}

\section{$\operatorname{AUTHOR}(S):$}

Ogasawara, Michio; Di Lauro, Roberto; Satoh, Nori

\section{CITATION:}

Ogasawara, Michio ...[et al]. Ascidian homologs of mammalian thyroid transcription factor-1 gene are expressed in the endostyle. Zoological Science 1999, 16(3): 559-565

ISSUE DATE:

1999-06

URL:

http://hdl.handle.net/2433/57227

RIGHT:

(c) 日本動物学会 / Zoological Society of Japan 


\title{
Ascidian Homologs of Mammalian Thyroid Transcription Factor-1 Gene Are Expressed in the Endostyle
}

\author{
Michio Ogasawara ${ }^{1 *}$, Roberto Di Lauro ${ }^{2}$ and Nori Satoh ${ }^{1}$ \\ ${ }^{1}$ Department of Zoology, Graduate School of Science, Kyoto University, \\ Sakyo-ku, Kyoto 606-8502, Japan \\ ${ }^{2}$ Laboratory of Biochemistry and Molecular Biology, Stazione Zoologica Anton Dohrn, \\ Villa Communale, 8012 Naples, Italy
}

\begin{abstract}
The endostyle is a special organ in the pharynx of urochordates, cephalochordates and cyclostomes. During evolution of the primitive chordates, the endostyle was organized in their common ancestor(s) with a shift to internal feeding for extracting suspended food from the water. In addition, the endostyle has an iodine-concentrating activity and is therefore thought to be functionally homologous to the vertebrate thyroid gland. Human TITF1 and mouse titf1 are members of the Nkx-2.1/TTF-1 gene subfamily, which encode an NK-2 type homeodomain transcription factor. The genes are expressed in the thyroid gland and are essential for thyroid-specific structural gene expression. In the present study, we isolated cDNA clones for ascidian homologs of titf 1 from Halocynthia roretzi and Ciona intestinalis, and examined whether the genes are expressed in the ascidian endostyle. Results clearly indicated that both the $\mathrm{H}$. roretzi homolog Hrtitf1 and the $C$. intestinalis homolog Cititf1 are expressed specifically in the endostyle. The present finding therefore provide molecular evidence for the functional relationship between the ascidian endostyle and vertebrate thyroid gland. However, the genes are expressed in the supporting element regions but not in the putative iodine-concentrating regions of the endostyle.
\end{abstract}

\section{INTRODUCTION}

We are interested in molecular developmental mechanisms underlying the evolution of chordate body plan. The phylum Chordata consists of the subphyla Urochordata (tunicates), Cephalochordata (amphioxus) and Vertebrata. Chordates are categorized as deuterostomes, together with two other non-chordate invertebrate groups, echinoderms and hemichordates, as supported by molecular phylogenic studies (Wada and Satoh, 1994; Turbeville et al., 1994) as well as cladistic analysis (Schaeffer, 1987; Peterson, 1995). Chordates share several characteristic features including a notochord, a dorsal hollow nerve cord, and pharyngeal gill slits (e.g., Brusca and Brusca, 1990; Willmer, 1990; Nielsen, 1995; Gee, 1996). In addition, lower chordates including tunicates, amphioxus and larval lampreys share an endostyle. These are hallmarks of the chordate body plan. Therefore, investigations of molecular developmental mechanisms involved in the organization of these structures are of salient importance in attempts to understand the evolution of chordate body plan.

We have emphasized that these characteristic features of chordates seem to have evolved with the emergence of tadpole larva-like creatures (Satoh and Jeffery, 1995; Satoh,

\footnotetext{
* Corresponding author: Tel. +81-75-753-4095; FAX. +81-75-705-1113.
}

1995). Coincidently with this change in the mode of larval locomotion, most of the primitive chordates or chordate ancestors shifted their feeding system to the use of the pharyngeal gill slits for extracting suspended food from the water and the endostyle for secreting mucus to catch the food particles. The ascidian endostyle forms a trough-shaped structure in the ventral wall of the pharynx which extends from the fore-part of pharynx to the esophagus (see Fig. 4C; Ogasawara et al., 1996 and references therein). The cells of this organ are differentiated into eight or nine strips or zones that run parallel to one another in longitudinal orientation. The cells of each zone are highly specialized in morphology and function (Barrington, 1957, 1958; Fujita and Nanba, 1971; Thorpe et al., 1972; Dunn, 1974, 1980). Because the cells of zones 7,8 and 9 have an iodine-concentrating activity, as do the thyroid cells of higher vertebrates, the endostyle of lower chordates is commonly considered a homolog and primitive antecedent of the vertebrate thyroid gland (e.g., Barrington, 1957; Thorpe et al., 1972; Dunn, 1974, 1980).

In previous studies, to obtain insights into the molecular mechanisms responsible for the formation and function of the endostyle, we isolated cDNA clones for the endostyle-specific genes HrEnds1 and HrEnds2 from the ascidian Halocynthia roretzi (Ogasawara et al., 1996) and CiEnds1, CiEnds2, and CiEnds3 from the ascidian Ciona intestinalis (Ogasawara and Satoh, 1998). All of these genes encode 
secreted proteins. Interestingly, HrEnds2, CiEnds1 and CiEnds2 are expressed in zone 6 and encode similar secreted proteins, suggesting a molecular marker commonly used to monitor the ascidian endostyle differentiation. Because these genes encode structural proteins, we next focus on ascidian homologs of transcription factor genes that are expressed in the thyroid cells of higher vertebrates. The Nkx-2.1/TTF-1 genes TITF1 (human) and titf1 (mouse) belong to the family of NK-2 type homeobox containing genes (Harvey, 1996). They are involved in the thyroid-specific gene expression (Civitareale et al., 1993) and organogenesis of the thyroid (Kimura et al., 1996). In the present study, we investigated whether ascidian homologs of the thyroid-specific transcriptional factor gene Nkx-2.1/TTF-1 are expressed in the endostyle. Our results clearly indicated that the ascidian homologs of $N k x-2.1$ are expressed specifically in the endostyle.

\section{MATERIALS AND METHODS}

\section{Biological materials}

Adults and juveniles of $H$. roretzi and $C$. intestinalis were collected near the Otsuchi Marine Research Center, Ocean Research Institute, University of Tokyo, Iwate, and the Marine BioSource Education Center of Tohoku University, Onagawa, Miyagi, Japan. After the dissection of adult specimens, tissues and organs were fixed for in situ hybridization or quickly frozen in liquid nitrogen and kept at $-80^{\circ} \mathrm{C}$ until use.

\section{Isolation of RNAs}

Total RNA was extracted from various organs including the endostyle, pharyngeal gill, body wall muscle, intestine, gonad, and digestive gland of $H$. roretzi and $C$. intestinalis by the AGPC method (Chomczynski and Sacchi, 1987). Poly(A) ${ }^{+}$RNA was purified with oligotex dT30 beads (Roche Japan, Tokyo).

\section{RT-PCR amplification}

Reverse-transcription (RT) was carried out using $H$. roretzi endostyle Poly $(A)^{+}$RNA with hexanucleotide mix (Boehringer Mannheim, Heidelberg, Germany). After purification of the cDNA, degenerated polymerase chain reaction (PCR) was performed using two degenerated primers. In order to amplify the DNA fragment of NK-2 type homeodomain, the first-round PCR was done using primers NKX-F1 (5'-TTYAG-YCARGCNCARGTNTAYGARYT-3') and NKX-R (5'KTTYTGRAA-CCADATYTTNACYTG-3') (shown by IUPAC code). After the purification of DNA of the expected size from agarose gel, the DNA was used for the second-round PCR with the same primers. The PCR conditions were 30 cycles of $94^{\circ} \mathrm{C}$ for $1 \mathrm{~min}, 50^{\circ} \mathrm{C}$ for $2 \mathrm{~min}$, and $72^{\circ} \mathrm{C}$ for $30 \mathrm{sec}$ for both rounds.

\section{Isolation and sequencing of cDNA clones for an ascidian titf1 gene}

The DNA fragment isolated by RT-PCR was subcloned into the EcoRV site of the vector pBluescript II SK(-). cDNA clones for $H$. roretzi titf (Hrtitf1) were obtained by screening the $H$. roretzi endostyle cDNA library with this DNA fragment as the probe. Plaques which showed positive hybridization were selected and isolated by two rounds of screening. The specificity of the clones positive for the endostyle was confirmed by a Northern blot analysis. The clones were prepared for sequencing by controlled nested deletion from either the T3 or T7 side and sequenced using the ABI PRISM 377 DNA Sequencer (Perkin Elmer, Norwalk, CT, USA). The isolation and characterization of cDNA clones for $C$. intestinalis titf1 (Cititf1) were reported elsewhere (Ristoratore et al., submitted).

\section{Northern blot analysis}

The Northern blot hybridization was carried out by the standard procedure (Sambrook et al., 1989), and the filters were washed under high-stringency conditions. DNA probes for blot hybridizations were labeled with $\left[{ }^{32} \mathrm{P}\right]-\mathrm{dCTP}$ using a random primed labeling kit (Boehringer Mannheim).

\section{In situ hybridization}

Tissues of $H$. roretzi and $C$. intestinalis were fixed in $4 \%$ paraformaldehyde in $0.5 \mathrm{M} \mathrm{NaCl}, 0.1 \mathrm{M}$ MOPS buffer at $4^{\circ} \mathrm{C}$ for $12 \mathrm{hr}$. For the young adult $H$. roretzi, the tunic was stripped off with a razor-knife prior to fixation as above. In the case of young adult $C$. intestinalis, the specimens were treated with L-menthol seawater to induce relaxation of the body-wall muscle, and then the tunic was stripped off with tungsten needles in the fixation buffer. Probes were synthesized by following the instructions from the kit supplier (DIG RNA Labeling kit; Boehringer Mannheim). The in situ hybridization of whole-mount specimens was carried out basically as described previously (Ogasawara et al., 1996). For the in situ hybridization of sectioned specimens, samples were dehydrated with a graded series of alcohol, embedded in polyester wax (BDH) and sectioned at $10 \mu \mathrm{m}$.

\section{RESULTS}

\section{Isolation and characterization of cDNA for Hrtitf1 of Halocynthia roretzi}

With the aid of the conserved NK-2 type homeodomain sequence of Nkx-2.1/TTF-1, we amplified a target fragment from the adult endostyle poly $(A)^{+}$RNA by RT-PCR. After confirming that the fragment contained the predicted sequence of the NK-2 type homeodomain, we screened the $\mathrm{H}$. roretzi endostyle cDNA library (Ogasawara et al., 1996) with the fragment as a probe, and obtained candidate cDNA clones.

Fig. 1 shows the nucleotide and predicted amino acid sequences of cDNA for the $H$. roretzi Hrtitf1 gene. The nucleotide sequence will appear in the DDBJ, EMBL, and GenBank Nucleotide Sequence Databases under Accession No. AB017704. The sequence of the cDNA encompassed 2,820 bp including 19 adenylyl residues at the $3^{\prime}$ end. The ATG at the position 144-146 represented the putative start codon of the Hrtiff1-encoding protein. The cDNA contained a single open reading frame, which predicted the HrTTF-1 protein of 557 amino acids. The molecular mass of HrTTF-1 was calculated to be 60,038 . A data base search indicated that the polypeptide contained the TN domain at amino acid position 15-25, the homeodomain at 276-335, and the NK-2 domain at 415432, respectively (Fig. 1).

\section{Characterization of HrTTF-1}

The NK type homeobox genes were first cloned from Drosophila (Kim and Nirenberg, 1989), and four Drosophila genes so far isolated include NK1 (Dohrmann et al., 1990), NK2 (Jiminez et al., 1995), NK3 (Azpiazu and Frasch, 1993), and NK4 (Bodmer, 1993). The products of these genes were later classified into the two homeodomain protein classes, NK1 (containing NK1) and NK-2 (containing NK2 to NK4) (Burglin, 1993). NK-2 homeobox genes were isolated from various organisms (Harvey, 1996). At least five members of this family were isolated from mouse, including TTF-1/Nkx-2.1 (Oguchi 


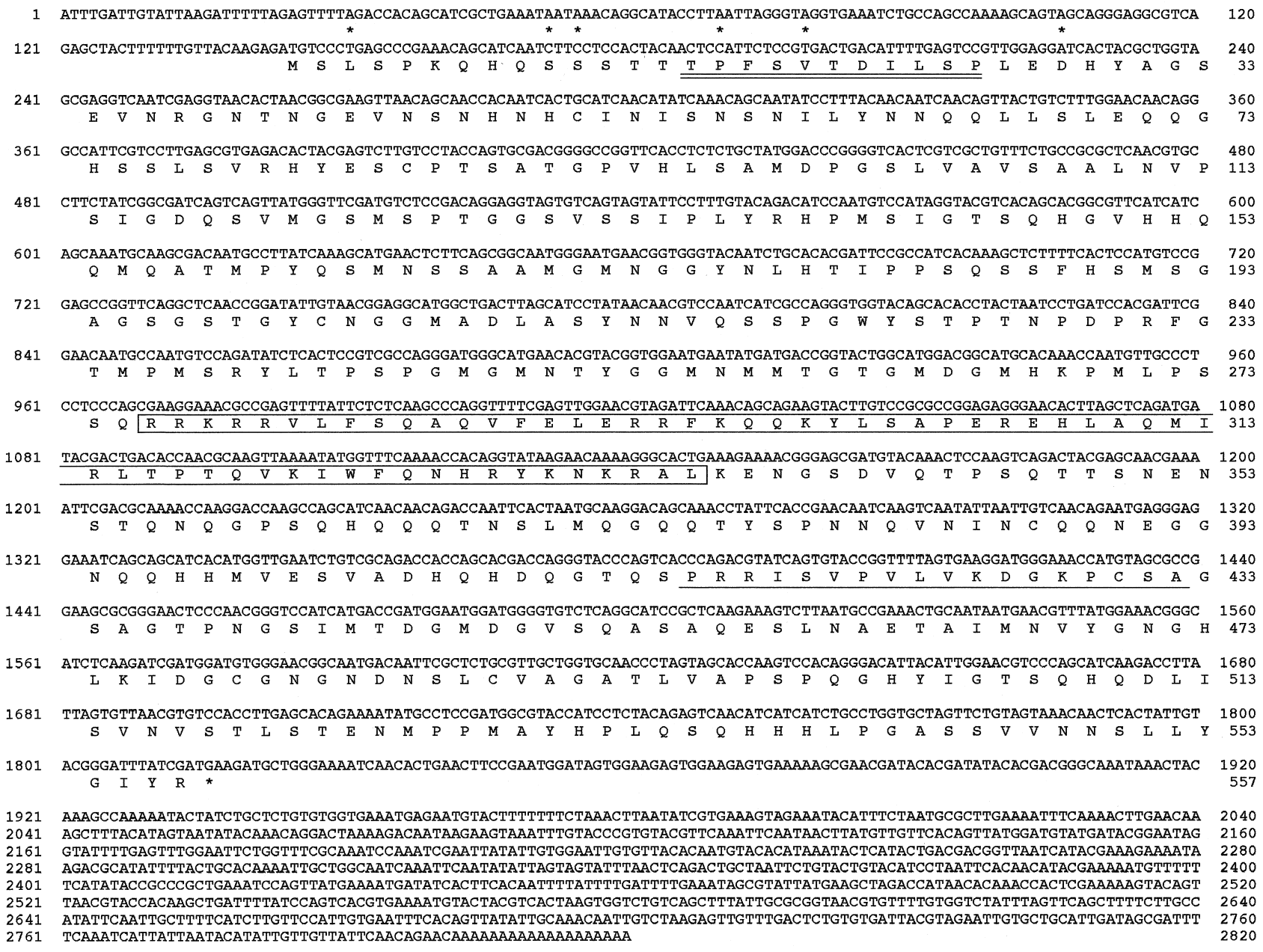

Fig. 1. Nucleotide and predicted amino acid sequences of cDNA for Hrtitf1 of Halocynthia roretzi. The sequence of the cDNA encompasses 2,820 bp including 19 adenylyl residues at the 3' end. The ATG at the position 144-146 represents the putative start codon of the Hrtitf1-encoding protein. An asterisk indicates the termination codon. The TN domain at amino acid portion 15-25 is double-underlined, the homeodomain at $276-$ 335 is boxed, and the NK-2 domain at 415-432 is underlined. The nucleotide sequence will appear in the DDBJ, EMBL, and GenBank Nucleotide Sequence Databases under Accession No. AB017704.

et al., 1995), Nkx-2.2 (Price et al., 1992), Nkx-2.3 (Price et al., 1992), and Nkx-2.5 (Lints et al., 1993). To identify subfamily to which HrTTF-1 belongs, we compared amino acid sequences of the HrTTF-1 TN domain (Fig. 2A) and homeodomain (Fig. 2B) with those of other Nkx-2 family members. First, it was noted that NK-2 type homeodomains (those of mouse Nkx-2.1, Nkx-2.2, Nkx-2.3 and Nkx-2.5, and Drosophila NK2, NK3 and NK4) share a tyrosine residue at position 54 within this domain. As was evident in Fig. 2B, the amino acid residue at position 54 of the HrTTF-1 homeodomain is tyrosine (arrow). This strongly suggests that HrTTF-1 is a member of the NK-2 family.

The amino acid sequence of the TN domain of HrTTF-1 was identical to that of CiTTF-1 (TTF-1 of $C$. intestinalis, see below; Fig. 2A; the Accession No. AJ009607). The grade of identity of this domain was about $90 \%$ between the ascidian (HrTTF-1 and CiTTF-1) and mammalian TTF-1/Nkx-2.1. However, the grade was relatively low between the ascidians and mammalian Nkx-2.2, Nkx-2.3 and Nkx-2.5. This suggests that
HrTTF- 1 is related to the Nkx-2.1 family.

A similar relationship was evident when we compared the amino acid sequences of the homeodomain (Fig. 2B). Only two amino acid residues were different between HrTTF-1 and CiTTF-1, the identity being $97 \%$. In addition, the degree of identity of the homeodomain was $90 \%$ between the ascidian HrTTF-1 and mammalian TTF-1/Nkx-2.1 (Fig. 2B). However, the identity decreased when compared between the ascidian HrTTF-1 and mouse Nkx-2.2 (83\%), Nkx-2.3 (82\%) or Nkx$2.5(78 \%)$. Furthermore, the degree of identity of this domain was about $82 \%$ between the ascidian HrTTF-1 and Drosophila NK2, but the degree was relatively low when compared with NK3 (65\%), NK4 (65\%), and NK1 (50\%). This strongly suggests that HrTTF- 1 and CiTTF- 1 are members of the Nkx2.1 family.

To test the above-mentioned results, we performed a molecular phylogenetic analysis. Using 60 confidently aligned sites of the homeodomain amino-acid residues, a molecular phylogenetic tree was constructed by the neighbor-joining 
A

\begin{tabular}{|c|c|c|}
\hline HrTTF-1 & TPFSVTDILSP & \\
\hline CiTTF-1 & $\ldots \ldots \ldots$ & $(100.0)$ \\
\hline Human TTF-1 & $\ldots . . . . .$. & $(90.9)$ \\
\hline Mouse TTF-1 & $\ldots$....... & $(90.9)$ \\
\hline Mouse $\mathrm{Nkx}-2.2$ & .G...K...DL & $(63.6)$ \\
\hline Mouse $\mathrm{Nkx}-2.3$ & $\ldots \ldots$....NL & $(72.7)$ \\
\hline Mouse $\mathrm{Nkx}-2.5$ & $\ldots \ldots K \ldots$ NL & $(72.7)$ \\
\hline
\end{tabular}

TN domain
B

HrTTF-1

CiTTF-1

Human TTF-1(Nkx-2.1)

Mouse TTF-1(Nkx-2.1)

Mouse $\mathrm{Nkx}-2.2$

Mouse $\mathrm{Nkx}-2.3$

Mouse $\mathrm{Nkx}-2.5$

Drosophila NK2

Drosophila NK3

Drosophila NK4

Drosophila NK1
RRKRRVLFSQAQVFELERRFKQQKYLSAPEREHLAQMIRLTPTQVKIWFQNHRYKNKRAL

\begin{tabular}{|c|c|}
\hline$\ldots \ldots \ldots \ldots \ldots$....... & $(96.7)$ \\
\hline$\ldots \ldots \ldots$....................QA & $(90.0)$ \\
\hline 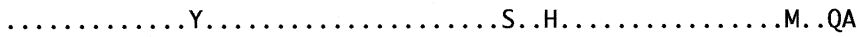 & $90.0)$ \\
\hline 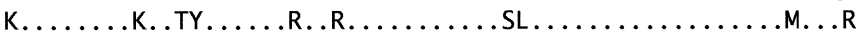 & $(83.3)$ \\
\hline$\ldots P \ldots \ldots \ldots \ldots \ldots \ldots$. . & $(81.7)$ \\
\hline 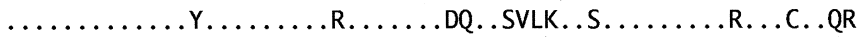 & $(78.3)$ \\
\hline 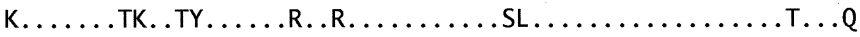 & $(81.7)$ \\
\hline KKRS.AA..H...........R...G...SEM.KSL ...E. & $(65.0)$ \\
\hline K..P.......L...C. RLK...TGA...II. .KLN.SA. & ⿹) \\
\hline 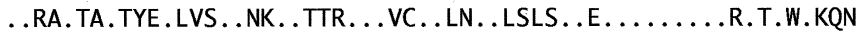 & \\
\hline
\end{tabular}

Fig. 2. (A) Comparison of amino acid sequences of the HrTTF-1 TN domain with those of CiTTF-1 and five mammalian NK-2-like gene products. The percentage of identity is shown at the right side. The dots represent identical amino acids. (B) Comparison of amino acid sequences of the HrTTF-1 homeodomain with those of CiTTF-1, five other mammalian NK-2-like gene products and Drosophila NK1 to NK4 gene products. The tyrosine at position 54 is a feature of NK-2 homeodomain proteins (arrow). Sources: CiTTF-1 (Ristoratore et al., submitted), human TTF-1 (Saiardi et al., 1995), mouse TTF-1 (Oguchi et al., 1995), mouse Nkx-2.2 (Price et al., 1992), mouse Nkx-2.3 (Price et al., 1992), and mouse Nkx-2.5 (Lints et al., 1993), Drosophila NK2 (Jiminez et al., 1995), Drosophila NK3 (Azpiazu and Frasch, 1993), Drosophila NK4 (Bodmer, 1993) and Drosophila NK1 (Dohrmann et al., 1990).

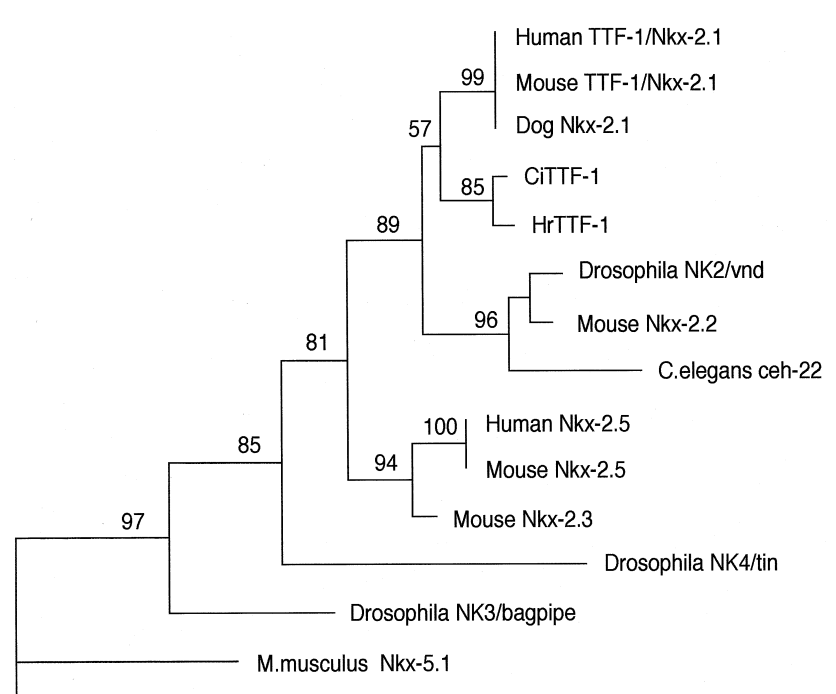

Drosophila NK1/S59

0.1

Fig. 3. Evolutionary relationships of HrTTF-1 with other NK-2 proteins. Using 60 confidently aligned sites of the homeodomain aminoacid residues, a molecular phylogenetic tree was constructed by the neighbor-joining method. The branch length is proportional to the number of amino acid substitutions; the scale bar indicates 0.1 amino acid substitutions per position in the sequence. The numbers at each branch indicate the percentage of times that a node was supported in 100 bootstrap pseudoreplications. method (Saitou and Nei, 1987). As shown in Fig. 3, the ascidian HrTTF-1 and CiTTF-1 form a discrete group with vertebrate Nkx-2.1 (mouse TTF-1/Nkx-2.1, human TTF-1/Nkx-2.1 and dog Nkx-2.1). This grouping was supported by the bootstrap value of $57 \%$. In addition, this group was included in a larger clade with Drosophila NK2, mouse Nkx-2.2 and C. elegans $\mathrm{CEH}-22$. This larger clade was supported by the bootstrap value of $89 \%$. From this data together with the results mentioned above, we concluded that HrTTF-1 and CiTTF-1 are members of the Nkx-2.1 family.

\section{Hrtitf1 is expressed in the endostyle}

The ascidian endostyle forms a trough-shaped structure in the ventral wall of the pharynx and extends from the forepart of the pharynx to the esophagus (Fig. 4C). The in situ hybridization of whole-mount specimens demonstrated that the Hrtitf1 signal was specific to the endostyle (Fig. 4A, B). No signal was detected in organs and tissues other than the endostyle. This was confirmed by Northern blot analysis. As shown in Fig. 4F, a distinct band of $2.8 \mathrm{~kb}$ was found in the endostyle. Although a very weak band was seen in the digestive gland (hepatopancreas), the signal was undetectable in the gonad, intestine, body-wall muscle and pharyngeal gill (Fig. $4 \mathrm{~F})$.

The endostyle cells are differentiated into eight or nine strips or zones and the cells of each zone are highly specialized in morphology and function (Fig. 4C; Barrington, 1957; Thorpe et al., 1972; Dunn, 1974, 1980). The cells of zones 7 , 8 and 9 have an iodine-concentrating activity, as do the thy- 

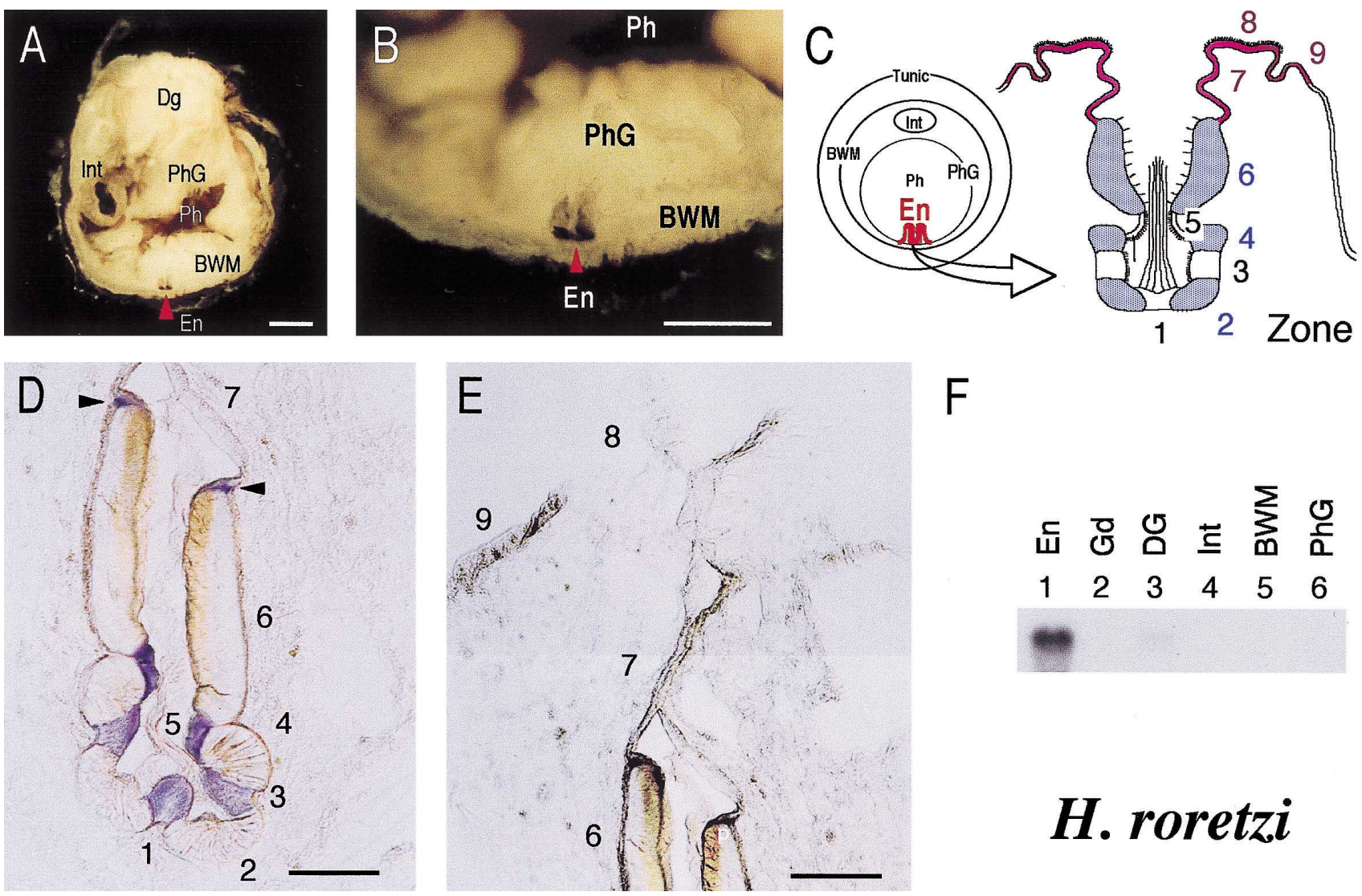

\section{H. roretzi}

Fig. 4. Expression of Hrtiff1 in the endostyle. (A, B) A whole-mount specimen of a 1-month-old young adult $H$. roretzi showing that the hybridization signal is restricted to the endostyle (En, red arrowhead). BWM, body-wall muscle; Dg, digestive gland; Int, intestine; PhG, pharyngeal gill; $\mathrm{Ph}$, pharynx. Scale bar is $1 \mathrm{~mm}$. (C) Diagram of the ascidian endostyle, showing compositional elements or zones of the endostyle. Zones 1 , 3 and 5 are supporting elements, zones 2, 4 and 6 are protein-secreting glandular elements, and zones 7, 8 and 9 are iodine-concentrating elements, equivalent to the thyroid gland of vertebrates. [Based on descriptions of Barrington (1957), Thorpe et al. (1972), Fujita and Nanba (1971), and Dunn (1974)]. (D, E) Cross-sections of the endostyle showing the gene expression in the entire zones of 1, 3 and 5 of the endostyle and in the basement region of the zone $6\left(\mathbf{D}\right.$, arrowheads). Scale bar is $100 \mu \mathrm{m}$. (F) Northern blots of poly $(A)^{+}$RNA prepared from the endostyle $(E n)$, gonad (Gd), digestive gland (DG), intestine (Int), body-wall muscle (BWM), and pharyngeal gill (PhG) were hybridized with random-primed $\left[{ }^{32} \mathrm{P}\right]$-labeled DNA probe, and the membrane was washed under high-stringency conditions. The Hrtitf1 transcript of about $2.8 \mathrm{~kb}$ in length was mainly detected in the endostyle. Each lane was loaded with $10 \mu \mathrm{g}$ of poly $(\mathrm{A})^{+} \mathrm{RNA}$.

roid cells of higher vertebrates. The cells of zones 2,4 and 6 have numerous secretory granules. These cells are believed to secrete the proteins or mucoprotein related to the digestion of food. The cells of zones 1,3 and 5 are considered supporting elements and also as elements that might play a role in catching and transporting food. The in situ hybridization of sectioned specimens demonstrated that the signal was not distributed over the entire area of the endostyle rather restricted to several zones (Fig. 4D, E). The transcript was evident in the entire region of zones 1,3 and 5 (Fig. 4D), and in basement region of the zone 6 (Fig. 4D, E). No signal was detected in zones 2, 4, 7, 8, and 9 (Fig. 4D, E).

\section{Cititf1 is also expressed in the endostyle}

The isolation and characterization of a cDNA clone for Cititf1 of $C$. intestinalis will be described in detail together with their expression pattern during Ciona embryogenesis, and experiments to deduce its function (Ristoratore et al., submitted). The present analysis of CiTTF-1 (Figs. 2 and 3) clearly indicated that CiTTF-1 is also a member of the Nkx-2.1 family.

The in situ hybridization of whole-mount specimens of a 1-month-old young adult $C$. intestinalis demonstrated that the signal was evident in the endostyle (Fig. 5A). No signal was detected in organs and tissues other than the endostyle. The Northern blot analysis supported this result. As shown in Fig. $5 \mathrm{D}$, a distinct band of $2.7 \mathrm{~kb}$ was found in the endostyle. The signal was undetectable in the pharyngeal gill, body-wall muscle, intestine, and gonad.

The in situ hybridization of sectioned specimens demonstrated that the signal was restricted to several zones of the endostyle (Fig. 5B, C). The Cititf1 transcript was found in the entire region of zones 3 and 5 (Fig. 5B), and in part of the regions of zones 1, 2 and 6 (Fig. 5B, C). As was the case for Hrtitf1, Cititf1 transcript was not found in the zones 7, 8, and 9 (Fig. 5B, C) with iodine-concentrating activity. 

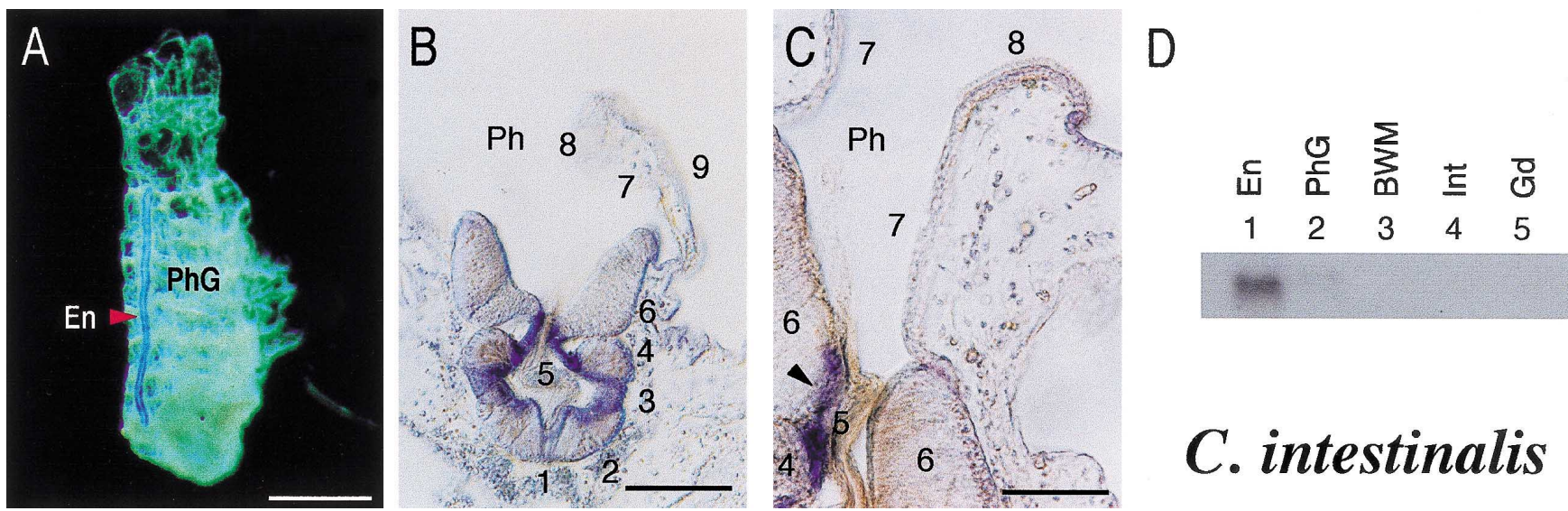

Fig. 5. Expression of Cititf1 in the endostyle. (A) A whole-mount specimen of a 1-month-old young adult $C$. intestinalis showing that the hybridization signal is restricted to the endostyle (En, red arrowhead). PhG, pharyngeal gill. Scale bar is $1 \mathrm{~mm}$. (B, C) Cross-sections of a young adult (scale bar is $100 \mu \mathrm{m}$ ) showing the Cititf1 gene expression in the entire zones of 3 and 5, and in part of the zones 1, 2 and 6 (arrowhead in C) of the endostyle. No signal is evident in the zones 7, 8 and 9, iodine-concentrating elements equivalent to the vertebrate thyroid gland. (D) Distribution of Cititf1 transcript in tissues and organs of the adult. Northern blots of poly $(A)^{+}$RNA prepared from the endostyle (En), pharyngeal gill (PhG), body-wall muscle (BWM), intestine (Int), and gonad (Gd) were hybridized with the random-primed [ $\left.{ }^{32} \mathrm{P}\right]$-labeled DNA probes, and the membrane was washed under high-stringency conditions. The Cititf1 transcript of about $2.7 \mathrm{~kb}$ in length was detected in the endostyle. Each lane was loaded with $8 \mu \mathrm{g}$ of $\operatorname{poly}(\mathrm{A})^{+} \mathrm{RNA}$.

\section{DISCUSSION}

The present study investigated ascidian homologs of the transcription factor gene TTF-1/Nkx-2.1, which is expressed in the thyroid gland of higher vertebrates (human, Saiardi et al., 1995; mouse, Oguchi et al., 1995; rat, Oguchi and Kimura, 1998; dog, Van Renterghem et al., 1995; and chick, Pera and Kessel, 1998). We isolated cDNA clones for the $H$. roretzigene Hrtitf1 and the $C$. intestinalis gene Cititf1. Both genes have a typical NK-2 type homeodomain (Fig. 2B) and are classified as members of the TTF-1/Nkx-2.1 family. The Northern blotting of adult tissues (Figs. 4F and 5D) and whole-mount in situ hybridization (Figs. 4A, 4B and $5 \mathrm{~A}$ ) clearly showed that the transcripts are present only in the endostyle. These results provide molecular evidence that the ascidian endostyle is homologous to the vertebrate thyroid gland.

The in situ hybridization of sectioned specimens showed that transcripts of Hrtitf1 are detected in the entire regions of zones 1, 3 and 5, and in part of the zone 6 . The Cititf1 transcript is also expressed in the entire regions of zones 3 and 5 , and in part of the zones 1,2 and 6 of the endostyle. As was mentioned above, zones 7, 8 and 9 are thought to be homologous to the thyroid cells of higher vertebrates, because the zones have an iodine concentration activity (Thorpe et al., 1972; Dunn, 1974) and thyroperoxidase activity (Fujita and Sawano, 1979). Interestingly, both Hrtitf1 and Cititf1 were not expressed in these zones with iodine-concentrating activity. Instead, Hrtitf1 was expressed primarily in the supporting zones and mucus secretion zones.

During the evolution of chordates, their ancestor(s) may have obtained an internal feeding system, using the pharyngeal gill slits and endostyle for extracting suspended food from the water. The endostyle of ascidians and amphioxus consists of two different regions, a mucus-secretory region and an iodine-concentrating region. The endostyle of larvae of cyclostomate lamprey has several cell types including protein secretory cells and iodine-concentrating cells (Fujita and Honma, 1968). During metamorphosis, the endostyle loses the protein secretory cells and transforms into the thyroid gland (Wright and Youson, 1976). The endostyle is therefore a key structure for clarifying not only the origin of chordates, but also the evolution to the thyroid gland of higher vertebrates. As shown in this study, Hrtitf1 and Cititf1 were not expressed in the region with iodine-concentrating activity but rather were expressed primarily in the supporting region and mucus secretion region as well. Therefore, further examinations of the pattern of titf1 expression (e.g., during the transformation of the endostyle of larval lamprey) are required to understand the relationships between the titf1 expression and formation of the thyroid-like organs during chordate evolution.

In previous studies, we isolated genes specific to the endostyle (Ogasawara et al., 1996; Ogasawara and Satoh, 1998). The HrEnds1, HrEnds2, CiEnds1 and CiEnds2 genes are expressed in the whole region of zone 6, CiEnds 3 in zone 2, and CiEnds 4 or a cytoplasmic actin gene in zones 3, 5 and 7 . Although the expression of the ascidian titf1 genes only partially overlap with that of these structural genes, it is an intriguing research subject to determine whether HrTTF-1 or CiTTF-1 regulates the expression of these structural genes.

\section{ACKNOWLEDGMENTS}

We thank all of the staff members of the Marine BioSource Education Center of Tohoku University, Onagawa, Miyagi and the Otsuchi Marine Research Center, Ocean Research Institute, University of Tokyo for their hospitality. We also thank Kazuko Hirayama for providing technical assistance. M.O. is a Predoctoral fellow of JSPS with a Monbusho research grant (No. 3252). This research was also supported by a Grant-in-Aid for Specially Promoted Research (No. 
07102012) to N.S. from Monbusho, Japan.

\section{REFERENCES}

Azpiazu N, Frasch M (1993) tinman and bagpipe: Two homeo box genes that determine cell fates in the dorsal mesoderm of Drosophila. Genes Dev 7: 1325-1340

Barrington EJW (1957) The distribution and significance of organically bound iodine in the ascidian Ciona intestinalis Linnaeus. $J$ Mar Biol Ass UK 36: 1-16

Barrington EJW (1958) The localization of organically bound iodine in the endostyle of Amphioxus. J Mar Biol Ass UK 37: 117-126

Bodmer R (1993) The gene tinman is required for specification of the heart and visceral muscles in Drosophila. Development 118: 719 729

Brusca RC, Brusca GJ (1990) Invertebrates. Sinauer Associates, Inc, Sunderland, MA, USA

Burglin TR (1993) A comprehensive classification of homeobox genes. In "Guidebook to the Homeobox Genes" Ed by D Duboule, Oxford Univ Press, Oxford, pp 25-71

Chomczynski P, Sacchi N (1987) Single-step method of RNA isolation by acid guanidinium thiocyanate-phenol-chloroform extraction. Anal Biochem 162: 156-159

Civitareale D, Castelli MP, Falasca P, Saiardi A (1993) Thyroid transcription factor 1 activates the promoter of the thyrotropin receptor gene. Mol Endocrinol 7: 1589-1595

Dohrmann C, Azpiazu N, Frasch M (1990) A new Drosophila homeo box gene is expressed in mesodermal precursor cells of distinct muscles during embryogenesis. Genes Dev 4: 2098-2111

Dunn AD (1974) Ultrastructural autoradiography and cytochemistry of the iodine-binding cells in the ascidian endostyle. J Exp Zool 188: $103-123$

Dunn AD (1980) Properties of an iodinating enzyme in the ascidian endostyle. Gen Comp Endocrinol 40: 484-493

Fujita H, Honma Y (1968) Some observations on the fine structure of the endostyle of larval lampreys, ammocoetes of Lampetra japonica. Gen Comp Endocrinol 11: 111-131

Fujita $H$, Nanba $H$ (1971) Fine structure and its functional properties of the endostyle of ascidians, Ciona intestinalis. A part of phylogenetic studies of the thyroid gland. Z Zellforsch Mikrosk Anat 121: 455-469

Fujita H, Sawano F (1979) Fine structural localization of endogeneous peroxidase in the endostyle of ascidians, Ciona intestinalis. A part of phylogenetic studies of the thyroid gland. Arch Histol Jpn 42: 319-326

Gee H (1996) Before the Backbone. Views on the Origin of the Vertebrates. Chapman \& Hall, London

Harvey RP (1996) NK-2 homeobox genes and heart development. Dev Biol 178: 203-216

Jiminez F, Marin-Morris LE, Velasco L, Chu H, Sierra J, Rossen DR, White K (1995) vnd, a gene required for early neurogenesis of Drosophila, encodes a homeodomain protein. EMBO J 14:34873495

Kim Y, Nirenberg M (1989) Drosophila NK-homeobox genes. Proc Natl Acad Sci USA 86: 7716-7720

Kimura S, Hara Y, Pineau T, Fernandez-Salguero P, Fox $\mathrm{CH}$, Ward JM, Gonzalez FJ (1996) The T/ebp null mouse: thyroid-specific enhancer-binding protein is essential for the organogenesis of the thyroid, lung, ventral forebrain, and pituitary. Genes Dev 10: 60-69

Lints TJ, Parsons LM, Hartley L, Lyons I, Harvey RP (1993) Nkx-2.5: A novel murine homeobox gene expressed in early heart progenitor cells and their myogenic descendants. Development 119: $419-431$
Nielsen C (1995) Animal Evolution. Interrelationships of the Living Phyla. Oxford Univ Press, Oxford

Ogasawara M, Tanaka KJ, Makabe KW, Satoh N (1996) Expression of endostyle-specific genes in the ascidian Halocynthia roretzi. Dev Genes Evol 206: 227-235

Ogasawara M, Satoh N (1998) Isolation and characterization of endostyle-specific genes in the ascidian Ciona intestinalis. Biol Bull 195: 60-69

Oguchi H, Pan YT, Kimura S (1995) The complete nucleotide sequence of the mouse thyroid-specific enhancer-binding protein (T/EBP) gene: extensive identity of the deduced amino acid sequence with the human protein. Biochim Biophys Acta 1261:304306

Oguchi H, Kimura S (1998) Multiple transcripts encoded by the thyroid-specific enhancer-binding protein (T/EBP)/thyroid-specific transcription factor-1 (TTF-1) gene: evidence of autoregulation. Endocrinology 139: 1999-2006

Pera EM, Kessel M (1998) Demarcation of ventral territories by the homeobox gene NKX2.1 during early chick development. Dev Genes Evol 208: 168-171

Peterson KJ (1995) A phylogenetic test of the calcichordate scenario. Lethaia 28: 25-38

Price M, Lazzaro D, Pohl T, Mattei MG, Ruther U, Olivo JC, Duboule D, Di Lauro R (1992) Regional expression of the homeobox gene $N k x-2.2$ in the developing mammalian forebrain. Neuron 8: $241-$ 255

Saiardi A, Tassi V, De Filippis V, Civitareale D (1995) Cloning and sequence analysis of human thyroid transcription factor 1 . Biochim Biophys Acta 1261: 307-310

Saitou N, Nei M (1987) The neighbor-joining method: a new method for reconstructing phylogenetic trees. Mol Biol Evol 4: 406-425

Sambrook J, Fritsch EF, Maniatis T (1989) Molecular Cloning: A Laboratory Manual. 2nd ed, Cold Spring Harbor Laboratory, Cold Spring Harbor, New York

Satoh N (1995) Towards a molecular understanding of developmental mechanisms underlying the origin and evolution of chordates. In "Biodiversity and Evolution" Ed by R Arai, M Kato, Y Doi, The National Science Museum Foundation, Tokyo, pp 267-290

Satoh N, Jeffery WR (1995) Chasing tails in ascidians: developmental insights into the origin and evolution of chordates. Trends Genet 11: 354-359

Schaeffer B (1987) Deuterostome monophyly and phylogeny. Evolutionary Biology 21: 179-235

Thorpe A, Thorndyke MC, Barrington EJ (1972) Ultrastructural and histochemical features of the endostyle of the ascidian Ciona intestinalis with special reference to the distribution of bound iodine. Gen Comp Endocrinol 19: 559-571

Turbeville JM, Schulz JR, Raff RA (1994) Deuterostome phylogeny and the sister group of the chordates: Evidence from molecules and morphology. Mol Biol Evol 11: 648-655

Van Renterghem P, Dremier S, Vassart G, Christophe D (1995) Study of TTF-1 gene expression in dog thyrocytes in primary culture. Mol Cell Endocrinol 112: 83-93

Wada H, Satoh N (1994) Details of the evolutionary history from invertebrates to vertebrates, as deduced from the sequences of 18S rDNA. Proc Natl Acad Sci USA 91: 1801-1804

Willmer P (1990) Invertebrate Relationships. Patterns in Animal Evolution. Cambridge Univ Press, Cambridge

Wright GM, Youson JH (1976) Transformation of the endostyle of the anadromous sea lamprey, Petromyzon marinus L., during metamorphosis. I. Light microscopy and autoradiography with ${ }^{125}$. Gen Comp Endocrinol 30: 243-257

(Received September 12, 1998 / Accepted January 11, 1999) 